\title{
JURISPRUDÊNCIA DEFENSIVA E IMPARCIALIDADE: O CONSUMIDOR NA BERLINDA
}

\section{DEFENSIVE JURISPRUDENCE AND IMPARTIALITY: CONSUMER ON THE SPOT}

\author{
${ }^{1}$ Miguel Luiz Barros Barreto de Oliveira
}

\section{RESUMO}

O presente artigo tem como principal objetivo avaliar possível desvirtuação das condenações por danos morais em processos consumeristas na atualidade. $O$ estudo se desenvolve em torno da legislação vigente, verificando a aplicação das indenizações a partir da jurisprudência obtida junto aos Tribunais pátrios. A construção do trabalho recorreu à análise da chamada jurisprudência defensiva, tanto no seu aspecto processual, que valoriza a racionalização excessiva das atividades do Poder Judiciário, como no seu aspecto material, que visa a rejeição de demandas repetitivas. Aborda a aplicação do princípio da imparcialidade objetiva neste contexto. Finalmente, discorre sobre a reparação do dano como método pedagógico e punitivo, até atingir resultado quanto a possível depreciação do referido instituto.

Palavras-chave: Direito do consumidor, Dano moral, Racionalização do processo, Imparcialidade, Caráter pedagógico e punitivo da reparação

\begin{abstract}
This article aims to evaluate possible distortion of convictions in compensation for moral damages in consumer lawsuits today. The study is based on the current law, examining the implementation of the compensation from decisions obtained from the Brazilian Courts. The work analyses the application of the so-called defensive jurisprudence, both in its procedural aspect, which values excessive rationalization of the judiciary activities, as in its material aspect, which aims to rejection of repetitive demands. This paper addresses the application of the principle of objective impartiality in this context. Finally, it discusses compensation for damage as a pedagogical and punitive method to reach a result as possible depreciation of the institute.
\end{abstract}

Keywords: Consumer law, Moral damage, Rationalization of the judiciary activities, Impartiality, Pedagogical and punitive character

\footnotetext{
${ }^{1}$ Mestre pela Universidade Católica de Petrópolis - UCP, Rio de Janeiro (Brasil). Professor em Direito pela Universidade Católica de Petrópolis - UCP, Rio de Janeiro (Brasil). E-mail: milbbo50@ hotmail.com
} 


\section{INTRODUÇÃO}

O presente trabalho é resultado de pesquisa que tem por escopo investigar o emprego, por parte dos tribunais brasileiros, em especial o Tribunal de Justiça do Estado do Rio de Janeiro, da chamada jurisprudência defensiva em relação a causas judiciais versando sobre relações consumeristas.

O fenômeno que vem sendo chamado de jurisprudência defensiva diz respeito à prática observada de formular entendimentos jurisprudenciais que acabam laborando como barreiras à análise do mérito dos recursos, em razão de uma excessiva rigidez no exame dos seus requisitos de admissibilidade. Para o tribunal, ela parece ter o objetivo de controlar o número de recursos a serem apreciados. Para os jurisdicionados, impacta negativamente no exercício do direito de recorrer, extensão do direito de ação.

Trata-se da racionalização imoderada das atividades exercidas pelo Poder Judiciário, rejeitando a continuação de demandas em busca de eficiência, mas que acaba restringindo, em certo sentido, o acesso ao Judiciário. Tudo em nome do cumprimento das metas de produtividade estipuladas pelo Conselho Nacional de Justiça, em especial a Meta 2.

A pesquisa a que se refere o presente trabalho parte da constatação de que a jurisprudência defensiva tem sucedido também no campo do direito material, especialmente no que toca os pleitos indenizatórios por danos morais. Esse fenômeno vem sendo verificando, especialmente, nas repentinas mudanças de entendimento a respeito dos casos repetitivos em que uma indenização, em tese, seria ou não devida, descuidando também do chamado aspecto "punitivo e pedagógico" da reparação.

É possível verificar diversas matérias que inicialmente, no tribunal pesquisado, seriam ensejadoras de condenação por danos morais e, mais tarde, passaram a ser consideradas apenas "mero aborrecimento", ao lado da alteração de entendimentos sobre requisitos de admissibilidade recursal, cada vez mais exigentes.

Isso leva a refletir que a celeridade ilusória objetivada neste "ativismo judicial processual", além de não resolver o gargalo do crescimento do número de ações, prejudica ainda mais o jurisdicionado - já lesado, em tese, na relação de consumo - menosprezando as condenações por danos morais. 
Tal alteração de entendimentos já sedimentados na jurisprudência coloca em dúvida a imparcialidade objetiva do Juízo para como o objeto do processo, principalmente em relação a problemas que geram grande quantidade de processos.

\section{RACIONALIZAÇÃO DO PROCESSO: JURISPRUDÊNCIA DEFENSIVA PROCESSUAL}

Observamos ser impossível afastar hodiernamente a combinação entre preservação da dignidade da pessoa e as relações de consumo. A Carta Magna de 1988 absorveu integralmente a ideia de defesa intransigente da dignidade humana e destacou sua valorização logo no art. $1^{\circ}$, inciso III. A dignidade da pessoa humana, fundamento da República Federativa do Brasil, é o princípio matriz de todos os direitos fundamentais.

Indispensável destacar ainda os artigos $5^{\circ}$, inciso XXXII e 170, inciso V, ambos da Constituição Federal, que consideram o direito do consumidor fundamental e essencial à ordem econômica do país, bem como os incisos $\mathrm{V}$ e $\mathrm{X}$, do citado art. $5^{\circ}$, estabelecem respectivamente, o direito à indenização por danos morais.

O artigo 48 do $\mathrm{ADCT}^{1}$ da Constituição previu a criação de um Código de Defesa do Consumidor, que entrou em vigor em 1991 (Lei 8.078/90), que, por sua vez, dispõe em seu artigo $6^{\circ}$, inciso VI, o direito à reparação.

Com efeito, é irrefutável reconhecer a possibilidade de indenização por danos morais, sendo o Codex Consumerista instrumento normativo eficaz para prevenir e proteger o consumidor das tentativas de lesão à sua dignidade. A defesa da dignidade do consumidor está prevista em legislação especial e garantida por norma constitucional que a alçou a direito fundamental.

A fim de esclarecer melhor este tema, antes de entrar no mérito da problemática, analisaremos antes dados referentes relativos às reclamações extrajudiciais e judiciais relativos a problemas de consumo nos últimos anos.

Consultando o site do Tribunal de Justiça do Estado do Rio de Janeiro observamos a evolução crescente do número de demandas envolvendo direitos do consumidor do ano de 2010 até 2015.

\footnotetext{
${ }^{1}$ Ato das Disposições Constitucionais Transitórias.
} 
Passamos neste momento a observar ${ }^{2}$ o total de processos distribuídos nos Juizados Especiais Cíveis no período destacado, que confirmam o aumento das demandas no período citado: em janeiro de 2010 foram distribuídos 23.744 processos distribuídos, sendo as dez empresas mais acionadas (1

- Light, 2 - Telemar Norte Leste, 3 - Ampla, 4 - Globex, 5 - Itaú, 6

- Casas Bahia, 7 - TNL PCS, 8 - Claro, 9 - Vivo, 10 - Bradesco); em janeiro de 2011 somou-se total de 25.959 processos distribuídos; em janeiro de 2012 um total de 29.125 processos distribuídos; em janeiro de 2013 foram 36.068 processos distribuídos, em janeiro de 2014 um total de 37.764 processos distribuídos e em janeiro de 201534.778 processos.

No mesmo sentido, o número de reclamações dirigidas às Agências Reguladoras também cresceu fortemente nos últimos anos. Cumpre destacar que existem dez Agências Reguladoras, criadas entre 1996 e 2001, que possuem o papel de regulamentar e fiscalizar a prestação de serviços públicos concedidos.

Optou-se por pesquisar junto às duas maiores Agências, quais sejam, Agência Nacional de Telecomunicação (ANATEL) e Agência Nacional de Energia Elétrica (ANEEL), que fiscalizam a prestação de serviços de telecomunicações e energia elétrica, bem como junto ao Banco Central, que não é Agência Reguladora, mas também tem a função de fiscalizar as atividades das instituições bancárias, recebendo reclamações por parte dos usuários do sistema. Os fornecedores fiscalizados por estes órgãos são os mais demandados na Justiça.

A primeira a ser destacada é Agência Nacional de Telecomunicação (ANATEL), sendo obtidos os resultados a partir do próprio sistema de registros de reclamações disponibilizado pela empresa e referente ao período compreendido entre os anos de 2009 a outubro de 2014 (ANATEL, 2014):

\begin{tabular}{|l|l|l|l|l|l|l|l|}
\hline $\begin{array}{c}\text { RECL. } \\
\text { OPERADORAS }\end{array}$ & $\mathbf{2 0 0 9}$ & $\mathbf{2 0 1 0}$ & $\mathbf{2 0 1 1}$ & $\mathbf{2 0 1 2}$ & $\mathbf{2 0 1 3}$ & $\mathbf{2 0 1 4}$ & TOTAL \\
\hline CLARO & 187.155 & 203.334 & 239.880 & 322.643 & 336.643 & 227.819 & 1.517 .474 \\
\hline CTBC & 3.985 & 7.835 & 9.196 & 13.097 & 14.833 & 7.587 & 56.533 \\
\hline EMBRATEL & 80.829 & 77.723 & 122.654 & 134.562 & 162.886 & 133.413 & 712.067 \\
\hline GVT & 21.934 & 14.113 & 21.229 & 57.304 & 153.590 & 107.873 & 376.043 \\
\hline NET & 43.073 & 45.234 & 47.914 & 71.399 & 103.431 & 107.773 & 418.824 \\
\hline
\end{tabular}

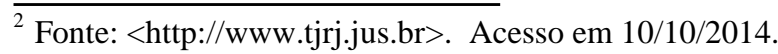




\begin{tabular}{|l|l|l|l|l|l|l|l|}
\hline NEXTEL & 2.542 & 6.008 & 16.051 & 34.701 & 32.207 & 50.192 & 141.701 \\
\hline OI & 494.797 & 527.593 & 599.761 & 901.667 & 1.220 .191 & 941.484 & 4.685 .493 \\
\hline OUTROS & 20.909 & 21.899 & 21.191 & 24.306 & 36.606 & 22.307 & 147.218 \\
\hline SERCOMTEL & 721 & 584 & 1.252 & 1.892 & 1.316 & 766 & 6.531 \\
\hline SKY & 8.702 & 14.914 & 22.346 & 69.917 & 90.856 & 103.822 & 310.557 \\
\hline $\begin{array}{l}\text { TELEVISÃO } \\
\text { CIDADE }\end{array}$ & 780 & 884 & 2.385 & 4.326 & 5.2111 & 3.261 & 16.847 \\
\hline TIM & 179.644 & 222.256 & 276.295 & 287.583 & 342.190 & 300.915 & 1.608 .883 \\
\hline VIACABO & 347 & 511 & 720 & 1.013 & 1.829 & 1.128 & 5.548 \\
\hline VIVO & 447.509 & 395.988 & 419.829 & 434.868 & 593.383 & 520.435 & 2.812 .012 \\
\hline TOTAL: & $\mathbf{1 . 4 9 2 . 9 2 7}$ & $\mathbf{1 . 5 3 8 . 8 7 6}$ & $\mathbf{1 . 8 0 0 . 7 0 3}$ & $\mathbf{2 . 3 5 9 . 2 7 8}$ & $\mathbf{3 . 0 9 5 . 1 7 2}$ & $\mathbf{2 . 5 2 8 . 7 7 5}$ & $\mathbf{1 2 . 8 1 5 . 7 3 1}$ \\
\hline
\end{tabular}

O segundo banco de registros de reclamações a ser observado é o do Banco Central, relativo ao período de 2010 a 2014 (BACEN, 2014). No ano de 2010 foram 124.751 reclamações enquanto que em 2014 foram registradas 295.868 reclamações. Observa-se que, apesar dos bancos serem um dos fornecedores mais acionados na Justiça ${ }^{3}$, existe pouca tradição de reclamação administrativa perante o Banco Central. O líder de reclamações mensais é o Banco Itaú, o segundo é o Banco Bradesco e o terceiro posto a Caixa Econômica Federal.

Apenas para exemplificar, no ano de 2011, entre as 25 (vinte e cinco) empresas mais acionadas em todo o país 23 (vinte e três) eram instituições financeiras. (CNJ, 2012) Neste período, as instituições financeiras participavam de $38 \%$ dos processos em trâmite no Brasil, empatadas com o setor público federal, sendo certo que alcançam o primeiro no lugar na justiça estadual, com 54\% dos processos. (CNJ 2012)

O terceiro registro a ser destacado é o da Agência Nacional de Energia Elétrica (ANEEL), referente ao período compreendido entre 2008 a 2013 (ANEEL, 2014). Em 2008, foram realizadas 53.010 (cinquenta e três mil e dez) reclamações, enquanto que em 2013 registrou-se 87.797 (oitenta e sete mil e setecentos e noventa e sete), expressivo crescimento de $40 \%$ (quarenta por cento) em cinco anos.

\footnotetext{
${ }^{3}$ No âmbito estadual, a pesquisa mostra que os bancos e o setor público (municipal, estadual e federal) foram responsáveis por $34,4 \%$ dos processos novos que chegaram à primeira instância entre janeiro e outubro de 2011. Nos Juizados Especiais, os bancos e o setor de telefonia figuram como os setores mais litigantes da Justiça Estadual, respectivamente com $14,7 \%$ e $8,3 \%$ do total de processos ingressados no período. Disponível em: <http://www.cnj.jus.br/noticias/cnj/21877-orgaos-federais-e-estaduais-lideram-100-maiores-litigantes-da-justica>. Acesso em 04/02/2015.
} 
Os dados acima citados desmistificam a ideia que o consumidor brasileiro seria "aventureiro", ou seja, que a maioria da população busca a Justiça para enriquecer indevidamente. Na verdade, a minoria reclama judicialmente. A maior parte dos problemas fica represado e não resolvido na seara extrajudicial. É o que nos diz os números.

É indispensável salientar que o número de reclamações citado é referente àquelas recebidas pelas principais Agências Reguladoras e pelo Banco Central, canais tradicionalmente e culturalmente pouco utilizados pelos consumidores para reclamar. Certamente, as reclamações recebidas diretamente pelos fornecedores que compõe o topo de empresas mais acionadas na Justiça deve ser ainda mais significativo.

Cotejando-se as informações supra citadas pode se chegar à conclusão que o aumento da quantidade de processos judiciais decorre do aumento proporcional das reclamações extrajudiciais em face dos fornecedores. Não existe corrida ao Judiciário. Os processos distribuídos espelham apenas o desrespeito crescente das empresas para com o consumidor, bem como a péssima prestação do serviço em solo nacional.

A partir desta constatação questiona-se o motivo das decisões proferidas pelos Tribunais, punirem cada vez menos, ou em valores menores, as condutas lesivas ao consumidor. A resposta pode ser encontrada pelo fato do Poder Judiciário, atualmente, preocupar-se cada vez mais com a racionalização do processo e cada vez menos com o julgamento justo e equilibrado dos litígios levados à sua apreciação, desconsiderando as consequências sociais provocadas por esta política.

Esta preocupação surgiu a partir do enorme crescimento da procura pelo Poder Judiciário, em especial os Juizados Especiais Cíveis. A Justiça virou refém da facilidade de se ter acesso à justiça, principalmente pela maior difusão dos direitos dos consumidores pela mídia, pelas organizações de defesa do consumidor e pelo próprio Poder Público. Até então habituais vítimas impotentes do mercado de consumo, os consumidores passaram a vislumbrar uma forma eficaz de resolver os seus problemas de forma rápida e financeiramente viável.

O Judiciário se viu inerte em face da eficiência do novel procedimento judicial instituído pela Lei 9.099/1995 que alterou completamente a percepção da população sobre a celeridade dos processos. Nas palavras do Presidente do Tribunal de Justiça do Estado do Rio de Janeiro: "Os Juizados, num paradoxo, foram vítimas do próprio sucesso. Começaram bem, e houve tanta procura que superou a estrutura." 
Após 20 anos da sua criação, o sistema dos Juizados responde por grande parte dos processos no Judiciário. O sistema administra, atualmente, 27\% dos 17,6 milhões de casos novos que chegam ao Judiciário Estadual, totalizando 4.804.855. Na Justiça Federal, a quantidade de casos novos em juizados especiais passou o número de casos registrados pela Justiça comum: 1,3 milhão contra 971 mil em 2013 - quase $60 \%$ da demanda.

Os números fazem parte do relatório Justiça em Números 2014, produzido anualmente pelo Conselho Nacional de Justiça.

Quando os juizados foram criados, esperava-se que fossem desviar ou reduzir o volume na Justiça comum, mas eles abriram uma porta para quem antes não tinha recurso para o Judiciário. Era uma demanda reprimida", aponta o ex- conselheiro do CNJ José Guilherme Vasi Werner, juiz titular de juizados especiais no Tribunal de Justiça do Rio de Janeiro.

Segundo o relatório do CNJ, enquanto o número de processos novos na Justiça comum de primeiro grau subiu 0,6 \% entre 2012 e 2013, nos juizados, subiu 13,5\%. Na Justiça Federal, o acréscimo foi de $0,5 \%$ nas varas comuns e de $18,6 \%$ nos juizados.

Era necessário buscar uma solução que não significasse aumento da estrutura física ou da contratação de novos servidores, tendo em vista a limitação imposta pela Lei de Responsabilidade Fiscal $^{4}$. A solução encontrada foi racionalizar o processo a fim de emprestar a celeridade exigida pelos órgãos de controle e fiscalização.

No entanto, os Tribunais passaram a racionalizar excessivamente o seu trabalho, em detrimento da observância das regras processuais e dos direitos envolvidos, principalmente com o fito de evitar a "multiplicação" de demandas repetitivas.

Justamente a partir do ano de 2009, quando foram implantadas metas pelo Conselho Nacional de Justiça, notamos esta mudança de discurso dos gestores do Judiciário nacional. Com efeito, as metas estipuladas pelo Conselho Nacional de Justiça consistem, basicamente, na união de esforços do Poder Judiciário em atender às seguintes demandas da sociedade: (...) redução de acervos de processos pendentes de julgamento - razoável duração do processo - aumento do volume de processos julgados - produtividade dos magistrados e servidores - (..). (CNJ, 2009)

\footnotetext{
${ }^{4}$ Lei Complementar n o 101, de 4 de maio de 2000. Disponível em: <www.planalto.gov.br〉. Acesso em 04/02/2015.
} 
Dentre as metas estabelecidas, destacou-se a "Meta 2" que se refere especificamente à necessidade de julgamento do maior número de causas possíveis, objetivando reduzir o acervo então existente, bem como julgar mais processos do que os distribuídos durante o ano:

O grande destaque foi a Meta 2, que determinou aos tribunais que identificassem e julgassem os processos judiciais mais antigos, distribuídos aos magistrados até 31.12.2005.

Com a Meta 2, o Poder Judiciário começou a se alinhar com o direito constitucional de todos os cidadãos brasileiros que estabelece a duração razoável do processo na Justiça. Foi o começo de uma luta que contagiou o Poder Judiciário do país para acabar com o estoque de processos causadores de altas taxas de congestionamento nos tribunais. (...) (CNJ, 2009)

Porém, para viabilizar o cumprimento da meta citada, os Tribunais passaram a adotar práticas que violam as normas processuais, tudo em nome de uma suposta busca pela "celeridade", mesmo que isso significasse mudança de posicionamentos jurisprudenciais então consolidados. Inicialmente, os tribunais de segunda instância passaram a represar os recursos para os tribunais superiores através do chamado juízo de admissibilidade, análise realizada pelos Tribunais de segunda instância sobre a possibilidade de prosseguimento dos recursos dirigidos aos Tribunais superiores.

Dados da Secretaria Judiciária do Supremo Tribunal Federal informam que: "Estima-se que o juízo de admissibilidade evita que 60\% dos recursos extraordinários do país cheguem ao Supremo, porque eles são barrados nos tribunais inferiores.” (O GLOBO, 2015)

O Tribunal de Justiça do Estado de São Paulo, responsável por cerca de 40\% do movimento de recurso especiais julgado pelo Superior Tribunal de Justiça, admite, historicamente, apenas 04\% dos REsp:

Entre janeiro e dezembro de 2014 a Presidência da Seção de Direito Privado analisou 129.978 recursos. Cerca $4 \%$ dos recursos foram admitidos e encaminhados ao STF ou STJ. Dos $96 \%$ que tiveram seguimento negado, aproximadamente $40 \%$ sofreu agravo e, desses, $10 \%$ obtiveram provimento com a subida dos recursos. (MIGALHAS, 2015)

Dados divulgados pelo Ministro Campbell Marques do Superior Tribunal de Justiça afirmam que: "Segundo Campbell Marques, dados do tribunal apontam que aproximadamente $48 \%$ dos pedidos de recursos são barrados com o dispositivo a ser extinto no novo CPC, em março de 2016." (CONJUR, 2015) 
A necessidade de maior "eficiência" na prestação jurisdicional atingiu o próprio Supremo Tribunal Federal. Com a chegada do ministro Ricardo Lewandowski à Presidência do Tribunal, o tema foi alçado ao status de prioridade ostensiva, que se manifesta na preferência para o julgamento de repercussões gerais que estejam retendo grandes volumes de recursos sobrestados, bem como na transferência de numerosas competências do Plenário para as Turmas.

O julgamento do RExt 592377 representa perfeito exemplo desta prática. Por sete votos a um o Tribunal declarou a constitucionalidade de medida provisória editada em 2001 que permitia, e ainda permite, a capitalização de juros.

A despeito da discussão de mérito, as manifestações dos Ministros revelam que as consequências deste julgamento, que afetou 13.584 (treze mil e quinhentos e oitenta e quatro) casos sobrestados nas instâncias inferiores, eram muito mais importantes do que a busca pela justa solução da questão. A exultante declaração do Ministro Ricardo Lewandowski após o julgamento foi emblemática: "Limpamos as prateleiras dos tribunais". (MIGALHAS, 2015)

Esta modificação de pensamento nem sempre trouxe benefício para a sociedade. O Ministro Marco Aurélio, do próprio Supremo Tribunal Federal, em entrevista ao site Consultor Jurídico, exemplificou o desvirtuamento da aplicação da "Meta 2" (CONJUR, 2014):

\begin{abstract}
A meu ver está havendo certo exagero na racionalização dos trabalhos em prejuízo da cidadania e dos cidadãos em geral. Ou seja, se está potencializando, para utilizar um português bem claro, a mais não poder, a autodefesa, tendo em conta a sobrecarga de processos. Mas a sobrecarga de processos não autoriza o órgão julgador a forçar a mão para se ver livre destes ou daqueles processos. $\mathrm{O}$ jurisdicionado não pode ser prejudicado."
\end{abstract}

O jusfilósofo Lênio Streck também percebeu com perspicácia o excesso de racionalização dos trabalhos do Judiciário que, em tom utilitarista, destaca a celeridade em detrimento da real valorização do direito do cidadão (STRECK, 2014):

De uns tempos para cá, o Superior Tribunal de Justiça vem fincando pé em entendimento cujo desígnio é, uma vez mais, obstar o exame de mérito dos recursos especiais, a ponto de robustecer seu extenso rol de jurisprudências defensivas que, no conjunto, fragilizam sobremodo o acesso à justiça em terrae brasilis. A lei, em grande parte das vezes, é jogada a um exílio epistêmico. A motivação? Utilitarista, é claro. E tudo em nome de efetividades quantitativas, com o sacrifício das efetividades qualitativas. 
A criação da chamada jurisprudência defensiva, que defende o excesso de formalismos para viabilizar a admissão de recursos, foi a primeira providência adotada para desaforar o Judiciário. Segundo André Luís Monteiro, no texto "Duas providências do projeto de novo Código de Processo Civil para o fim da chamada jurisprudência defensiva: uma evolução rumo ao pleno acesso à justiça”, a jurisprudência defensiva é um (MONTEIRO, 2014):

Exagero no exame formal dos requisitos de admissibilidade dos recursos, de maneira a abortar prematuramente o caminho desses remédios e, assim, aliviar a sobrecarga de trabalho dos julgadores, com a justificativa - de viés econômico - de que o tempo melhor aproveitado pode ser utilizado em casos de maior relevância.

Esta política provoca perplexidade e frustração ao jurisdicionando, além de consternar os patronos que, por receio de não ter seus recursos conhecidos, acabam por exceder-se em diversas hipóteses desnecessariamente, o que gera propositura de recursos sem cabimento. Maria Lúcia Lins Conceição, em seu texto “Jurisprudência Defensiva”, in Ideias \& Opiniões, lembra que:

As barreiras são tantas, muitas vezes sem qualquer suporte dogmático, que a parte, ao interpor um recurso, se sente envolvida em verdadeiras armadilhas. Isso sem contar a séria dúvida sobre a legalidade e legitimidade dessa prática como meio de atenuação da sobrecarga de trabalho dos tribunais. (CONCEIÇÃO, 2012)

Ao jurisdicionando interessa apenas se há ou não direito e razão em seu pleito. Os entraves à admissão dos recursos não resolvem este problema, apenas devolvem o litígio para a sociedade sem solução. Nesse sentido, torna-se necessário, na maioria das vezes, demandar novamente criando os processos conhecidos como "filhotes".

A solução para o enxugamento dos Tribunais não está na jurisprudência defensiva nem na rejeição sumária de direitos. A busca incessante pela efetividade das sentenças, a reestruturação do Poder Judiciário, o investimento em práticas conciliatórias e preventivas, a viabilização das tutelas coletivas e a modernização da legislação poderiam socorrer o cidadão sem a necessidade de supressão de garantias constitucionalmente estabelecidas.

Essa é a opinião do advogado José Miguel Garcia Medina, que participa da criação no anteprojeto do novo Código de Processo Civil (MEDINA, 2013): 
Tal é o que pode acontecer, creio, com aquilo que se convencionou chamar de jurisprudência defensiva. Acostumamo-nos com ela. Em nossos livros, escrevemos a respeito dos requisitos exigidos pela jurisprudência dos tribunais superiores, ainda que os mesmos não estejam amparados na Constituição, ou na lei. Em nosso dia a dia, na advocacia, já nos habituamos a ser surpreendidos por mudanças jurisprudenciais, novas orientações dos tribunais superiores que passam a exigir requisitos não previstos em regra jurídica alguma, e convivemos, sem questionamentos, com isso.

Com a finalidade de viabilizar o funcionamento do Superior Tribunal de Justiça, tornando-o "sustentável" (levando em conta o número de processos que poderia julgar), a jurisprudência passa a adotar postura não apenas mais rigorosa em relação aos requisitos recursais, mas vai além, impondo às partes a observância de exigências não previstas em qualquer norma jurídica.

(...) Os cidadãos, afinal, seriam os grandes culpados, já que recorriam em demasia àqueles tribunais.

Falar contra a jurisprudência defensiva, assim, é quase um pecado, pois demonstraria que o autor da crítica é insensível aos problemas dos tribunais.

Penso que temos que lutar contra esse nosso conformismo diante da jurisprudência defensiva. A mudança deve começar por nós mesmos."

O novo Código de Processo Civil visa amenizar a possibilidade de utilização da jurisprudência defensiva ao determinar em seu art. 945, parágrafo único que "antes de considerar inadmissível o recurso, o relator concederá o prazo de cinco dias ao recorrente para que seja sanado vício ou complementada a documentação exigível". Aprovando-se esta regra, o recorrente passará a ter direito à emenda do recurso, tendo em vista a previsão de uma espécie de juízo de admissibilidade em sede recursal.

De fato, a tentativa de redução do número de demandas constitui objetivo fundamental do Conselho Nacional de Justiça, o que se observa do discurso de seu ex-Presidente e Ministro do Supremo Tribunal Federal Gilmar Mendes, obtido junto ao site do próprio Conselho. (CNJ, 2013)

$\mathrm{Na}$ ocasião, de forma clara, pediu aos magistrados que, além de empenho nos julgamentos, buscassem uma reduzir sensivelmente o estoque de processos, reafirmando a importância de se cumprir as Metas estabelecidas pelo Conselho:

Não sou contra criação de novas Varas onde se fizer necessário, sobretudo em locais longínquos. No entanto, temos que refletir nossas necessidades e repensar esse modelo, tentando racionalizar o processo e ao mesmo tempo continuar a expansão da Justiça", destacou. Nesse sentido, o ministro pediu aos magistrados que, durante o workshop, discutam medidas concretas para garantir o cumprimento da Meta 2. (CNJ, 2013) 
A referida matéria destaca, ainda, o reconhecimento do sucesso da Justiça em dar respostas aos novos processos. Entretanto, reafirmou que todos os esforços empenhados não estão sendo capazes de reduzir o número de demandas ajuizadas, indicando a impossibilidade de se dar vazão ao estoque.

Na mesma linha de raciocínio, destaca-se artigo do Conselheiro do Conselho Nacional de Justiça, Dr. Ives Gandra Martins (CNJ, 2013) que aborda a mobilização judiciária com o fim de racionalizar os processos. Restou reconhecido que atingir esses requisitos não é tarefa nem simples, nem fácil e tem encontrado natural resistência numa cultura aferrada ao modelo vigente, marcado por uma lentidão, complexidade, ineficiência e personalismo na gestão da coisa pública, sendo certo que, neste contexto, a denominada "Meta 2" do Conselho Nacional de Justiça constituiu um marco para o mapeamento das deficiências estruturais do Judiciário brasileiro.

Com o natural aumento da demanda judicial, justamente pela ampliação do acesso ao Judiciário, as soluções gerenciais e de modernização tecnológica tendem a atingir os seus limites de elasticidade, sendo certo que a adoção de mecanismos de valorização das decisões dos Tribunais Superiores, como a repercussão geral e a súmula vinculante para o Supremo Tribunal Federal, o sistema de recursos repetitivos para o Superior Tribunal de Justiça e o critério de transcendência para o Tribunal Superior do Trabalho, serve como meio de aperfeiçoar os julgamentos.

O Tribunal de Justiça do Estado do Rio de Janeiro incorporou e difundiu esta mesma tese. No ano de 2013 foram inauguradas cinco Câmaras Cíveis especializadas em Direito do Consumidor. Nas palavras da então presidente Desembargadora Leila Mariano o objetivo era unificar o entendimento quanto às matérias recorrentes, julgando os processos com maior agilidade (CONJUR, 2013):

É necessário que haja uma produtividade constante e crescente, e isso só será possível se afinarem a jurisprudência entre si. Os senhores lidarão com demandas de massa, sendo fundamental o viés jurisprudencial para que não se crie demandas artificiais ou oportunistas.

Nota-se em seu discurso hialina preocupação em reduzir o estoque de processos, evitando o que conceitua como "demandas artificiais ou oportunistas". Não surpreende que as súmulas 199, 205, 228 e 230 do Egrégio Tribunal Estadual, amplamente desfavoráveis ao consumidor, 
que serão citadas no decurso deste trabalho, tenham origem em decisões proferidas pela r.

Desembargadora ex-Presidente após o ano de 2009.

O recém-eleito Presidente do mesmo Tribunal, Desembargador Luiz Fernando Ribeiro de Carvalho, também não passou ao largo da questão ao ser entrevistado pela revista Tribuna do Advogado (TRIBUNA DO ADVOGADO, 2015):

O Judiciário vai seguir o caminho de diminuir o número de processos. O Rio de Janeiro tem 9,5 milhões de ações, o que é um absurdo. Sabe quantos juízes temos? Cerca de 800. E temos que racionalizar nosso trabalho, utilizando meios alternativos de solução de conflitos, dar melhor rendimento para as ações coletivas, que podem conter até cem mil cidadãos. Cortar demanda sem deixar de sustentar direitos."

De fato, existe real preocupação em cumprir as metas citadas. Os dados (CNJ, 2013) abaixo demonstram que o Tribunal de Justiça do Estado do Rio de Janeiro cumpriu as "Metas 2" de 2012 e 2013, em 107,09\% e 107,08\%, respectivamente, sendo que o percentual de cumprimento da "Meta 2" de 2009 foi de $58,7 \%$ e da "Meta 2" de 2010 de 84,29\%.

Ou seja, o Tribunal de Justiça do Estado do Rio de Janeiro se preocupa seriamente em cumprir as metas desde o ano de 2009. Os números não mentem. O comparativo entre o crescimento de ações ajuizadas e a quantidade de julgamentos se torna relevante para demonstrar a falta de preocupação do Poder Judiciário em punir as empresas mais acionadas.

Neste capítulo demonstrou-se que o Poder Judiciário utiliza a jurisprudência defensiva processual como tentativa de racionalizar o processo. Todavia, a celeridade ilusória objetivada com esta manobra de "ativismo judicial processual", além de não resolver o problema do crescimento do número de ações, prejudica ainda mais o jurisdicionado. Os Tribunais acabaram criando um meio de bloquear o acesso à justiça à posteriori, ou seja, durante o transcorrer do processo.

\section{RACIONALIZAÇÃO DO PROCESSO: JURISPRUDÊNCIA DEFENSIVA MATERIAL}

Além da jurisprudência defensiva processual, abordada acima, os Tribunais vem criando outro tipo de jurisprudência defensiva, a qual denominaremos jurisprudência defensiva material, que é aquela que visa evitar a multiplicação de processos gerados por condutas repetidamente 
abusivas praticadas pelos fornecedores rejeitando o mérito das ações consumeristas respectivas e, assim, desestimulando a propositura de novos processos.

Igualmente, uma prática de restrição do acesso à justiça à posteriori, pois objetiva reduzir $\mathrm{o}$ número de processos criando jurisprudência manifestamente desfavorável ao consumidor, seja reduzindo consideravelmente o valor das indenizações ou mesmo julgando improcedentes os pedidos.

Com efeito, a análise dos casos concretos a seguir citados revela a drástica redução do valor das condenações, bem como a alteração de entendimentos sobre questões já pacificadas em favor do consumidor. Estas alterações ocorreram, em sua grande maioria, justamente no período em que houve maior cobrança pelo cumprimento de metas.

\subsection{LEGALIDADE DA COBRANÇA DE TARIFAS EM CONTRATOS DE FINANCIAMENTOS DE VEÍCULOS}

O primeiro caso a ser analisado refere-se às tarifas cobradas em contratos de financiamento de veículos. Até meados de 2011, o entendimento majoritário do Conselho Recursal do Tribunal de Justiça do Estado do Rio de Janeiro era o de reconhecer a ilegalidade de cobranças, condenando as financeiras a restituir em dobro os valores pagos pelos consumidores, com fulcro no art. 42 da Lei 8.078/1990, além de condenar ao pagamento de indenização por danos morais, vide acórdão do processo $\mathrm{n}^{\mathrm{o}}$ 0017651-31.2011.8.19.0042.

Após o julgamento da Reclamação no 4.892/PR (2010/0186855-4) pelo Superior Tribunal de Justiça, cujo relator foi o Ministro Raul Araújo, que considerou a necessidade de demonstração da má-fé do fornecedor para exsurgir o direito à devolução em dobro, foi modificado o entendimento do Conselho, que passou apenas a condenar pela devolução de forma simples dos valores cobrados.

Em 18/09/2012, a Comissão dos Juizados Especiais - COJES $^{5}$ deliberou por 11 votos a 5, em uniformização de jurisprudência das cinco Turmas Recursais, que a contar de 01/10/2012, que não incidiria mais indenização por danos morais nem repetição do indébito referente a cobranças de tarifas indevidas, alterando novamente o entendimento menos de um ano depois

No dia 28/08/2013 o Egrégio Superior Tribunal de Justiça, através de julgamento de recurso no rito dos repetitivos (REsp 1.251.331), definiu três teses que deveriam servir de

\footnotetext{
${ }^{7}$ Disponível em: <www.tiri.ius.br>. Acesso em 12/12/2014.
} 
parâmetro para análise dos processos paralisados referentes a cobrança de tarifas, liberando a cobrança apenas da tarifa de "cadastro".

A partir deste julgamento, o posicionamento do Conselho Recursal foi modificado mais uma vez, agora para julgar totalmente improcedentes os pedidos, nos termos da decisão unânime do Conselho Recursal proferida no processo $\mathrm{n}^{\circ}$ 0007951-44.2014.8.19.0036.

Nota-se que o Egrégio Tribunal Superior não se manifestou sobre a legalidade das demais tarifas, se limitando a afirmar que a tarifa de cadastro poderia ser cobrada. No entanto, o Conselho em tela interpretou a decisão de forma extensiva, entendendo então que a cobrança de todas as tarifas seriam legais.

A outro giro, o Colendo Tribunal de Justiça do Estado do Rio de Janeiro interpretou a decisão do Superior Tribunal de Justiça de forma diversa, apenas declarando a legalidade da tarifa de cadastro, mas mantendo o consolidado entendimento de que a cobrança das demais tarifas continuaria a ser abusiva, vide a decisão da $27^{\mathrm{a}}$ Câmara Cível do Consumidor no processo $\mathrm{n}^{\circ}$ 002365868.2013.8.19.0042. Ou seja, dois órgãos revisores do mesmo Tribunal têm entendimentos totalmente distintos em relação à mesma matéria.

\subsection{LEGALIDADE DA SUSPENSÃO TEMPORÁRIA DE SERVIÇO DE TELEFONIA E DE FORNECIMENTO DE ENERGIA ELÉTRICA}

Não se pode deslembrar do julgamento do Conselho Recursal no caso conhecido como “apagão" de telefonia ocorrido no município de Petrópolis (RJ) no ano de 2008. Milhares de consumidores das operadoras Claro e Telemar Norte Leste, atualmente denominada Oi Móvel, ficaram sem utilizar seus telefones celulares por duas semanas consecutivas. Mais de 8.000 (oito mil) ações foram propostas na Comarca de Petrópolis referentes a este problema. ${ }^{6}$

Os dois Juízes titulares do I e II Juizado Especial Cível reconheceram os danos suportados pela população e condenaram os réus a pagar indenização por danos morais. Todavia, quando os primeiros recursos chegaram à apreciação do Conselho Recursal, chegou-se à decisão unânime

\footnotetext{
${ }^{7}$ Disponível em: <www.tjrj.jus.br>. Acesso em 11/11/2014.
} 
em todas as Turmas, ${ }^{7}$ que a situação vivenciada pelo consumidor petropolitano era apenas "mero aborrecimento" não indenizável.

Em outros casos, o Conselho Recursal do Tribunal de Justiça também alterou seu entendimento, reduzindo drasticamente os valores anteriormente fixados ou julgando improcedente os pedidos, como no caso de suspensão indevida do fornecimento de energia elétrica residencial. Em acórdão proferido no ano de 2009 (processo $\mathrm{n}^{\circ}$ 000085736.2009.8.19.0031), reconheceu-se o direito à indenização. Já em 2014, em caso semelhante, foi rejeitado o pleito (processo $\mathrm{n}^{\circ}$ 0133487-73.2014.8.19.0001).

Esta última decisão, na realidade, segue duas súmulas aprovadas recentemente pelo Egrégio Tribunal de Justiça, de ns. ${ }^{\circ} 192$ e $193^{8}$ :

Súmula 192. A indevida interrupção na prestação de serviços essenciais de água, energia elétrica, telefone e gás configura dano moral.

Súmula 193. Breve interrupção na prestação dos serviços essenciais de água, energia elétrica, telefone e gás por deficiência operacional não constitui dano moral.

A primeira reconhece como passível de indenização a interrupção indevida da prestação de serviços de natureza essencial como água, telefone e luz, ao passo que a segunda súmula indica que a breve interrupção de serviços desta natureza não geram danos morais.

O caráter excessivamente genérico do conteúdo da súmula no 193 acaba abrindo espaço para interpretações contrárias à defesa do consumidor hipossuficiente que precisa utilizar os serviços essenciais, proporcionando grande quantidade de sentenças de improcedências neste tipo de caso.

\subsection{LEGALIDADE DA COBRANÇA INDEVIDA DE SERVIÇOS NÃO SOLICITADOS}

A outro giro, seguindo na linha de falhas cometidas por instituições bancárias, destacamos os casos de cobranças de tarifa para manutenção de cartões de crédito que encontravam-se bloqueados. Inicialmente, era reconhecida a ilegalidade, com consequente condenação das instituições a devolver os valores cobrados de forma indevida, bem como arcar com pagamento

\footnotetext{
${ }^{7}$ Inclusive, o teor da decisão era idêntico em todas as Turmas Recursais.

${ }^{8}$ Disponível em: <www.tjrj.jus.br>. Acesso em 05/02/2015.
} 
frente aos transtornos suportados, conforme decisão emanada no processo no 0009699 19.2011.8.19.0036 em 28/06/2012. Posteriormente, o entendimento foi modificado, nos termos da decisão visualizada no processo $n^{\circ}$ 0023367-68.2013.8.19.0042 de 12/02/2014.

Outro caso que merece enfoque são os julgamentos referentes a cobranças indevidas por serviços não contratados e vinculados aos serviços de telefonia como, por exemplo, as cobranças do plano $\mathrm{LDN}^{9}$, que inicialmente eram passíveis de condenação por danos morais pelo Conselho em análise, vide processo ${ }^{\circ}$ 0092749-85.2012.8.19.0042 de 11/07/2013, acabaram consideradas apenas transtorno patrimonial, conforme acórdão proferido no processo $\mathrm{n}^{\circ}$ 002019866.2013.8.19.0206 de 25/11/2014.

\subsection{JULGAMENTOS RECENTES DO SUPERIOR TRIBUNAL DE JUSTIÇA SOBRE QUESTÕES DE CONSUMO}

Não foi só no caso específico das tarifas que o Superior Tribunal de Justiça mudou entendimento para banalizar as condenações por danos morais em sede consumerista.

O Recurso Especial 1.399.931, de relatoria do ministro aposentado Sidnei Beneti, versava sobre caso em que o consumidor adquiriu um tablet pela internet para presentear o filho no Natal, sendo certo que mercadoria não foi entregue, o que gerou a propositura de demanda indenizatória. De acordo com Beneti, a jurisprudência do Superior Tribunal de Justiça é categórica: aborrecimentos comuns do dia a dia, "os meros dissabores normais e próprios do convívio social, não são suficientes para originar danos morais indenizáveis". Segue afirmando que a falha na entrega da mercadoria adquirida pela internet configura, em princípio, "mero inadimplemento contratual, não dando causa a indenização por danos morais".

Com esse julgamento, a $3^{\text {a }}$ Turma do Superior Tribunal de Justiça, de maneira unânime, decidiu que não são devidos danos morais ao consumidor que adquire pela internet mercadoria para presentear e não a recebe conforme o ajustado.

No mesmo sentido, a $4^{\mathrm{a}}$ Turma, também de maneira unânime, deliberou que atraso em voo doméstico inferior a oito horas não gera dano moral. Decisão proferida pelo Ministro Luis Felipe Salomão, no julgamento do Recurso Especial 1.269.246, entendeu que a verificação do dano moral "não reside exatamente na simples ocorrência do ilícito", pois nem todo ato em

\footnotetext{
${ }^{9}$ Ligação à distância nacional.
} 
desacordo com o ordenamento jurídico possibilita indenização por dano moral. Para ele, o importante é que "o ato seja capaz de irradiar-se para a esfera da dignidade da pessoa, ofendendo- a de maneira relevante". Por isso, Salomão diz que o "mero inadimplemento contratual" não se revela bastante para gerar dano moral.

Em relação à esta decisão impossível não destacar o caso em que um Juiz de Direito deu ordem de prisão a funcionários de empresa aérea que negaram seu embarque devido ao seu atraso em se apresentar no check-in. Ou seja, o consumidor aguardar 08 (oito) horas para embarque é situação de "mero aborrecimento". Por outro lado, quando a situação ocorre com o Juiz que chega atrasado é caso de "prisão".

O então Ministro Massami Uyeda, relator do Recurso Especial 1.234.549, asseverou que a tendência do Superior Tribunal de Justiça era buscar rejeitar indenizações por dano moral na hipótese em que há apenas "aborrecimentos aos quais todos estão sujeitos”.

No caso em comento, os consumidores compraram imóvel em um condomínio residencial pelo valor de R\$95 mil e, após a mudança, constataram diversos problemas como infiltrações, vazamentos e imperfeição do acabamento. Tais fatos geraram danos aos móveis da residência e problemas de saúde no filho dos proprietários em consequência do mofo.

Os recorrentes pleitearam a rescisão contratual, a devolução do valor pago e a condenação em danos morais no valor de R 20 mil. Conforme o ministro, os problemas ocorridos no apartamento, embora tenham causado frustração, por si sós não justificam indenização por danos morais. Para ele, mesmo que os defeitos de construção tenham sido constatados pelas instâncias de origem, "tais circunstâncias não tornaram o imóvel impróprio para o uso".

Em outro julgamento da $4^{\text {a }}$ Turma, os ministros decidiram que a aquisição de produto impróprio para o consumo, quando não há ingestão, configura hipótese de mero dissabor vivenciado pelo consumidor, o que afasta qualquer pretensão indenizatória. A discussão se deu no julgamento do Recurso Especial 489.325, de relatoria do ministro Marco Buzzi. A ação foi movida por um consumidor que comprou uma lata de extrato de tomate com odor e consistência alterados. A lata de extrato possuía colônias de fungos.

Buzzi afirmou que o vício constatado no produto autoriza a indenização por dano material, correspondente ao valor efetivamente pago. Entretanto, como não houve ingestão do produto, a condenação do fabricante em danos morais ficou afastada, "em razão da inexistência de abalo físico ou psicológico vivenciado pelo consumidor". 
No Recurso Especial 1.444.573, os Ministros da $3^{\mathrm{a}}$ Turma afastaram o dano moral em ação de reparação proposta por policial militar que alegou constrangimento ao ficar travado na porta giratória de uma agência do Banco Santander porque estava armado.

Indispensável destacar o recente julgamento do Superior Tribunal de Justiça sobre o sistema de avaliação de crédito denominado scoring ou credit score. Milhares de consumidores intentaram ações em todo Brasil contra o sistema score de crédito, com o objetivo de declarar a inscrição no Concentre Scoring ilegal. Objetivava-se a condenação do prestador das informações ao cumprimento da obrigação de fazer para que o mesmo se abstivesse de prestar as informações constantes no sistema e, em consequência, condenando-o ao pagamento de indenização por danos morais.

Tal ação era fundamentada no direito do consumidor ser avisado da abertura de cadastro creditício em seu nome, com fulcro no art. 43, parágrafo $2^{\circ}$ do Código do Consumidor, bem como sobre a falta de informação sobre os critérios utilizados pelo sistema. Muitos consumidores deram início às ações diante das diversas decisões jurisprudenciais que se mostravam favoráveis aos mesmos. Tendo em vista o número repetitivo de ações, restou determinada a suspensão de todas até o julgamento da matéria nas superiores instâncias, a fim de evitar a "multiplicação" das ações.

O Superior Tribunal de Justiça, através de sua Segunda Seção, ao julgar os Recursos Especiais (REsp) n n 1.457 .199 e 1.419.697, declarou, por unanimidade, que o sistema era legal e não gerava mácula ao nome do consumidor.

Ressaltou que: "a metodologia é segredo empresarial e não precisa ser divulgada, bem como que não se pode exigir o prévio e expresso consentimento do consumidor avaliado, até porque isto poderia levar à inoperabilidade do sistema”, bem como "não gerando dano moral indenizável, nem havendo a necessidade de prévia comunicação ao consumidor avaliado, lembrando que sempre se deve respeitar os basilares princípios consumeristas e os direitos legalmente assegurados aos consumidores." 


\subsection{ANÁLISE DAS SÚMULAS APROVADAS RECENTEMENTE PELO TRIBUNAL DE JUSTIÇA DO ESTADO DO RIO DE JANEIRO SOBRE QUESTÕES DE CONSUMO}

Neste mesmo viés interpretativo, o Tribunal de Justiça do Estado do Rio de Janeiro tem adotado para julgamento critérios que escapam à realidade das práticas adotadas no mercado de consumo. Com efeito, as súmulas do Tribunal de Justiça aprovadas a partir do ano de 2009, além das supra citadas, são, em sua grande maioria, desfavoráveis ao consumidor, vide os entendimentos abaixo citados (TJ-RJ, 2015), verbis:

\footnotetext{
No. 149 "Nas ações indenizatórias decorrentes da contratação do "cartão megabônus", os danos morais não podem ser considerados in re ipsa, cumprindo ao consumidor demonstrar a ofensa à honra, vergonha ou humilhação, decorrentes da frustração da expectativa de sua utilização como cartão de crédito."

No. 199 "Não configura dano moral o simples aviso, ainda que sem amparo legal, de interrupção de serviço essencial, salvo em caso de comprovada repercussão externa."

No. 205 "A limitação judicial de descontos decorrentes de mútuo bancário realizados por instituição financeira em conta corrente, no índice de 30\%, não

enseja ao correntista o direito à devolução do que lhe foi antes cobrado acima do percentual, nem a conduta configura dano moral."

$\mathrm{N}^{\circ} .228$ "O simples aviso encaminhado por órgão restritivo de crédito, desacompanhado de posterior inscrição, não configura dano moral."

REFERÊNCIA: Processo Administrativo $n^{\circ} .0013649$ 47.2011.8.19.0000

No. 230 "Cobrança feita através de missivas, desacompanhada de inscrição em cadastro restritivo de crédito, não configura dano moral, nem rende ensejo à devolução em dobro."

No. 280 "O simples disparo do alarme antifurto em estabelecimentos comerciais, só por si, não caracteriza lesão extrapatrimonial, ressalvados os episódios de desnecessária e inconveniente exposição ou grosseira abordagem da pessoa, a serem aferidos caso a caso."
}

Os Tribunais não têm considerado o caráter pedagógico-punitivo das condenações por danos morais. Ao revés, não punindo as empresas, o efeito é contrário: estimula os fornecedores a não investir na melhoria dos serviços, o que acaba gerando ainda mais problemas e reclamações, tanto extrajudicialmente quanto judicialmente. A opção pela adoção da jurisprudência defensiva material torna possível atingir metas e aumentar padrões de produtividade, mas acaba por banalizar a dignidade do consumidor, que é tratado como apenas mais um número na capa do processo.

A crítica é reiterada, mas ainda não suficiente para permitir maior reflexão dos Juízes, vide recente manifestação do presidente da Associação dos Magistrados Brasileiros, Dr. João Ricardo Costa (CONJUR, 2015): 
Para João Ricardo, a argumentação tem como objetivo interditar o debate. "O mais sensato seria rebater os nossos argumentos à luz da realidade", diz. "Cada vez que apresentamos uma proposta para racionalizar o processo recebemos a resposta que não queremos trabalhar."

Ele aponta que os juízes estão no limite de sua capacidade laboral, mas que o principal problema é a falta de racionalidade do sistema processual brasileiro.

Tal política traz ainda maior descrédito da população em relação ao Poder Judiciário, cujo índice de confiança, conforme recente pesquisa realizada pela Fundação Getúlio Vargas, é de apenas 32\%. Índice de confiança inferior ao da Polícia. (FGV, 2014)

Para Luciana Gross Cunha, coordenadora do Índice de Confiança na Justiça (ICJBrasil), a baixa confiança é explicada pela incapacidade do Judiciário em corresponder às expectativas da sociedade: “O cidadão está insatisfeito porque o Judiciário presta mal o serviço. É um sistema falido — porque não consegue responder em tempo hábil — e muito caro para o erário. Quando o Judiciário dá uma resposta, ela é insatisfatória".

Não é possível aceitar que um princípio fundamental da República seja barateado apenas para viabilizar a busca por celeridade que somente prejudica o cidadão e, principalmente, o consumidor.

\section{IMPARCIALIDADE OBJETIVA}

A problemática em tela demonstra que estamos que estamos diante de uma colisão de princípios e garantias constitucionais. Por um lado, a fim de possibilitar o cumprimento das metas de produtividade, o Poder Judiciário defende a aplicação extremada do princípio da celeridade processual, através da criação da jurisprudência defensiva (processual e material), a fim de desafogar o estoque dos Tribunais.

Por outro lado, verificamos que tal medida abalroa frontalmente as garantias de imparcialidade do Juiz, derivadas do princípio do Juiz natural, que não pode julgar influenciado por interesses próprios ou por pressões externas. Diante desse conflito, qual princípio deve preponderar? Qual tem a maior importância no caso concreto? Qual deve ter o maior peso? O equacionamento da celeridade e segurança jurídica sempre foi um desafio para o sistema processual brasileiro.

Todavia, a busca pela rapidez nunca deve afetar a imparcialidade do Juiz. A imparcialidade do juiz não é mais visualizada como mera característica da função jurisdicional. É 
hodiernamente considerada como fundamental e essencial para o aperfeiçoamento do ato jurisdicional.

No contexto desta digressão, imparcial é o juiz que não tenha interesse no objeto do processo. O magistrado não pode ser influenciado pelas consequências de sua decisão, mas apenas que sua sentença seja compromissada com a justiça. Apesar de todos os esforços para atingir a neutralidade nos julgamentos como forma de manter imaculada a imparcialidade, percebe-se claramente que o Estado-Juiz tem dentro do processo uma vontade.

Seu objetivo na entrega da tutela estatal perfaz o cumprimento do "justo". Sua vontade e seu agir cumpre-se independentemente do caráter subjetivo verificado na ação que lhe é colocada à análise, daí porque, quando a sentença reconhece o direito de uma das partes, está na verdade, fazendo cumprir a finalidade objetiva do Estado, para qual não interessa saber qual o objeto do direito em análise.

A imparcialidade é um quesito essencial na justiça. As partes tem o direito a um julgamento imparcial, ou seja, que não prejudica ou favorece qualquer delas, especialmente devido à pressões externas de toda natureza, mesmo quando se trata de cumprimento de metas.

Para se chegar a justiça é preciso que o processo seja justo. E para que o processo seja justo é estritamente necessário que o juiz seja imparcial e independente, não só em relação às partes, mas também em relação a eventuais interesses que ele próprio tiver no processo, inclusive o cumprimento de metas. O Juiz somente tem o dever de se submeter à Lei, desde que constitucional, nunca a um objetivo interna corporis.

Pois bem. O exercício legítimo e legal da jurisdição pressupõe que, no caso concreto, o magistrado o faça não só com imparcialidade subjetiva, mas também com a chamada imparcialidade objetiva, que deriva não da relação do juiz com as partes, e sim de sua relação com os fatos da causa cuja apreciação lhe é submetida.

A imparcialidade objetiva determina que o juiz não tenha pré-julgamentos acerca dos fatos da causa. Esses pré-juízos podem derivar do contato anterior do juiz com os fatos e fundamentos jurídicos de processos idênticos ou semelhantes, em especiais os repetitivos.

Este tipo de situação transparece a falta dessa imparcialidade objetiva, que viola o devido processo legal (CF, art. $5^{\circ}$, LIV).

É possível se falar em violação ao princípio do Juiz natural neste caso, já que a decisão decorrente está eivada de parcialidade intrínseca. O Poder Judiciário não pode jurisdicionalizar 
seus próprios interesses. As razões da fundamentação das decisões não podem ser turbadas por um único e irracional objetivo, qual seja, o cumprimento de metas.

Em verdade nem mesmo se deveria ponderar esses valores, pois não existe incompatibilidade entre eles. A busca pela celeridade nunca deverá ofuscar o valor justiça. Lenio Streck esposou esse posicionamento quando abordou a dicotomia entre celeridade e necessidade de fundamentação das decisões impostas pelo novo CPC:

ConJur - Se forem pesados os dois valores, o que é mais importante: a celeridade processual ou a fundamentação das decisões?

Lenio Streck — Essa é uma falsa questão, uma falsa dicotomia. Não se pode colocar uma contra a outra.

O processo não pode ter objetivo outro senão a busca pela escorreita prestação jurisdicional. O processo é um meio e não um fim em si próprio. $\mathrm{O}$ objeto do processo é a relação, fatos ou atos jurídicos judicializados, e nada mais, conforme ensina Hernando Echandía (ECHANDÍA, 1997, p. 156):

El objecto de todo processo judicial es la relación jurídica o los actos jurídicos o los hechos, a la cual o la cuales debe aplicarse en el caso concreto las normas que los regulan, para decidir sobre sua existência o sus efectos jurídicos.

O foco do processo contemporâneo está cada vez mais afastado de seu aspecto técniconormativo e cada vez mais próximo de seu destinatário final, o cidadão.

O processo não pode ter objetivos próprios; não pode ser instrumento para o exercício (abusivo) do poder; não pode ser utilizado como ferramenta para consecução de metas administrativas.

\section{CONCLUSÃO}

O presente trabalho procurou demonstrar as soluções adotadas pelos Tribunais para diminuir o crescente estoque de processos, seja pela adoção da jurisprudência defensiva processual ou material.

Apesar de objetivar a redução da carga de processos e recursos, as medidas ensejaram a propositura de ainda mais recursos, bem como não evitaram o crescimento dos litígios de 
consumo. Espera-se que esta mentalidade seja modificada, a fim de possibilitar um processo mais justo.

O consumidor merece ser tratado de forma digna, sendo certo que se não houver severa punição em face dos fornecedores não se mudará a realidade atualmente vivenciada. A mudança de posicionamento em tela chama a atenção, tendo em vista que o número de processos de consumo distribuídos perante os tribunais aumentou significativamente nos últimos anos.

A tendência natural seria que as condenações se tornassem mais severas, a fim de desestimular as condutas lesivas, nunca mais brandas. Não se pode olvidar que o dano moral possui caráter punitivo-pedagógico, que objetiva justamente punir quem reincide no ato ilícito, prejudicando, muita das vezes, milhares de consumidores com a mesma prática abusiva. Nicolau Maquiavel resume a efetividade da punição pecuniária em poucas e duras palavras: "O homem esquece mais facilmente a morte do pai do que a perda do patrimônio."

No entanto, esta característica não vem sendo observada pelos Tribunais. Na realidade, a natureza punitiva é cada vez menos valorizada. Esta observação se faz necessária quando se reconhece que situações potencialmente causadoras de danos possam alcançar significativo número de pessoas, sendo necessária a aplicação de indenização com função de desacorçoar as empresas a praticar atos refratários.

A professora Maria Celina Bodin destaca com primor a necessidade de emprestar viés punitivo às lesões à dignidade do consumidor (BODIN, 2009, p. 231-232):

É de aceitar-se, ainda, um caráter punitivo na reparação de dano moral para situações potencialmente causadoras de lesões a um grande número de pessoas, como ocorre nos direitos difusos, tanto na relação de consumo quanto no Direito Ambiental. Aqui, a ratio será a função preventivo-pedagógica, que o caráter punitivo inegavelmente detém, em relação às dimensões do universos a ser protegido.

(...)

De fato, não são poucos os que hoje afirmam que a satisfação do dano moral visa, além de atenuar o sofrimento injusto, desafrontar o inato sentimento de vingança, retribuindo o mal com o mal; prevenir ofensas futuras, fazendo com que o ofensor, não deseje repetir tal comportamento; e servir de exemplo, para que tampouco se queira imitá-lo. Diz-se, então, que a reparação do dano moral detém um duplo aspecto, constituindo-se por meio de um caráter compensatório, para confortar a vítima - ajudando a sublimar as aflições e tristezas decorrentes do dano injusto --, e de um caráter punitivo, cujo objetivo, em suma, é impor uma penalidade exemplar ao ofensor, constituindo esta diminuição de seu patrimônio material e na transferência da quantidade para o patrimônio da vítima. 
O crescimento do número de processos distribuídos é exponencial. Nota-se também que as empresas mais acionadas são sempre as mesmas, o que comprova a falta de eficácia das condenações impostas pelo Poder Judiciário.

O número de reclamações extrajudiciais também aumenta a cada ano, em números ainda maiores do que as reclamações judiciais. A frenética valorização da celeridade não deve, nem pode, açoitar direitos, pois a rapidez do julgamento dos processos deve favorecer fundamentalmente o cidadão, não apenas a Justiça, conforme se depreende das sábias palavras do Professor José Rogério Cruz e Tucci (TUCCI, 2015), verbis:

Não obstante, em nossa experiência jurídica, esquecendo completamente de que a celeridade deve servir às partes e não ao Estado, os tribunais, em várias situações, extrapolam as garantias processuais, passando a legislar em detrimento do direito material do litigante, como ocorre, por exemplo, no âmbito da famigerada jurisprudência defensiva.

Deixar de condenar o fornecedor por ofender o consumidor em processo individual, criando jurisprudência desfavorável, é deixar de punir a empresa pela mesma conduta perpetrada perante milhares de outros que se encontram na mesma situação. Nas sábias palavras de Montesquieu: "A injustiça feita a um é ameaça feita a todos".

Desse modo, concluímos que enquanto os fornecedores não forem severamente punidos pelos seus atos contrários à dignidade do consumidor (causa do problema), obrigando-os a melhorar o serviço prestado, o número de reclamações e, por conseguinte, de processos judiciais (efeito do problema) não será reduzido, sendo a jurisprudência defensiva material instrumento ineficaz, parcial e, principalmente, injusto para este fim.

\section{REFERÊNCIAS BIBLIOGRÁFICAS}

AGÊNCIA NACIONAL DE TELECOMUNICAÇÕES, Dados estatísticos de reclamação por operadora. Disponível em <www.anatel.gov.br>, acesso em 10/06/2015.

AGÊNCIA NACIONAL DE ENERGIA ELÉTRICA. Disponível em: <www.aneel.gov.br〉. Acesso em 04/02/2015.

BANCO CENTRAL DO BRASIL, Ranking das Instituições por Índice de Reclamações. Disponível em: <http://www.bcb.gov.br/?RANKING〉. Acesso em 04/02/2015. 
BRASIL. Constituição (1988). Constituição da República Federativa do Brasil. Brasília, DF: Senado Federal, 1988.

. Lei 8.078/1990, de 11/09/1990. Código de Defesa do Consumidor. Brasília, DF: Senado Federal.

CONCEIÇÃO, Maria Lúcia Lins. Jurisprudência Defensiva, in Ideias \& Opiniões, informativo do escritório Wambier \& Arruda Alvim Wambier, ano IX, nº 17, julho 2012.

CONSELHO NACIONAL DE JUSTIÇA, Metas Nacionais, disponível em: $<$ (http://www.cnj.jus.br/gestao-e-planejamento/metas)>. Acesso em 10/10/2014.

100 maiores litigantes, disponível em:

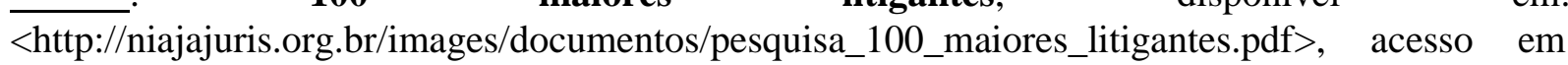
$10 / 07 / 2015$.

Justiça em números 2014, disponível em: <http://www.cnj.jus.br/images/pesquisasjudiciarias/documentos_jn/estadual.swf >. Acesso em 04/02/2015.

ECHANDÍA, Hernando Devis, Teoria General del Proceso, Editorial Universidad, Buenos Aires, 1997, pág. 156.

FUNDAÇÃO GETÚLIO VARGAS. Biblioteca digital. Disponível em: <http://bibliotecadigital.fgv.br/dspace/bitstream/handle/10438/12024/Relat\%C3\%B3rio\%20ICJB rasil\%20-\%20ano\%205.pdf?sequence=1\&isAllowed=y $>$. Acesso em 02/02/2015.

MIGALHAS, TJ/SP demonstra que sanção do novo CPC não alterou a distribuição de recursos, disponível em: $\quad$ http://www.migalhas.com.br/Quentes/17\%2cMI219108\%2c21048$\mathrm{TJ}+\mathrm{SP}+$ demonstra+que+sancao+do+novo+CPC+nao+alterou+distribuicao+de+recursos$>$.

Acesso em 17/07/2015.

MP que regula capitalização de juros é válida, declaração do Ministro está disponível em: <http://www.migalhas.com.br/Quentes/17,MI215141,71043$\mathrm{MP}+$ que+regula+capitalizacao+de+juros+e+valida>. Acesso em 04/03/2015.

MONTEIRO, André Luís. Duas providências do projeto de novo Código de Processo Civil para o fim da chamada jurisprudência defensiva e uma evolução rumo ao pleno acesso à justiça. Revista de Processo, vol. 204, Fev/2012.

MORAES, Maria Celina Bodin de. Danos à Pessoa Humana. Rio de Janeiro: Renovar, 2003.

O GLOBO ON LINE. Estudo mostra que o novo CPC inundará corte de recursos, $<$ http://epoca.globo.com/tempo/expresso/noticia/2015/03/estudo-do-stf-mostra-que-novo-cpcinundara-corte-de-recursos.html>, disponível em 15/06/2015. 
O GLOBO ON LINE, Em imperatriz juiz da ordem de prisão a funcionários da TAM, disponível em: <http://g1.globo.com/ma/maranhao/noticia/2014/12/em-imperatriz-juiz-da-ordem- de-prisaofuncionarios-da-tam.html>. Acesso em 04/02/2015.

REVISTA CONSULTOR JURÍDICO, Restrição ao HC: "Exagero na racionalização dos trabalhos dos tribunais prejudica cidadania", Marco Aurélio Mello. Disponível em: $<$ http://www.conjur.com.br/2014dez-21/entrevista-marco-aurelio-ministro-supremo-tribunal federal?utm_source=dlvr.it\&utm_medium=facebook>. Acesso em 21/12/2014.

Justiça gratuita: Recurso bom é recurso morto: é assim que pensam os tribunais?, Lênio Streck. Disponível em: <http://www.conjur.com.br/2014-dez-29/recurso-bom-recurso- mortoassim-pensam-tribunais>. Acesso em 10/01/2015.

Pelo fim da jurisprudência defensiva: uma utopia?, José Miguel Garcia Medina. Disponível em: <http://www.conjur.com.br/2013-jul-29/processo-fim-jurisprudencia-defensivautopia>. Acesso em 10/12/2014.

TJ-RJ implanta câmaras de direito do consumidor. Disponível em:

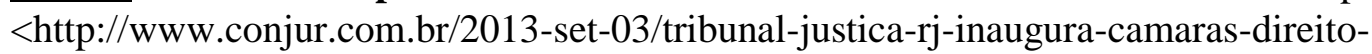
consumidor>. Acesso em 10/12/2014.

Dois importantes precedentes judicias salvaram a inusitada semana, José Rogério Cruz e Tucci. Disponível em: <http://www.conjur.com.br/2015-mar-03/paradoxo-corte-doisimportantes-precedentes-judicias-salvaram-inusitada-

semana?utm_source=dlvr.it\&utm_medium=facebook $>$. Acesso em 04/02/2015.

Racionalização do processo: Objetivo da magistratura é a celeridade, não reduzir o trabalho, diz AMB, João Ricardo Costa, Disponível em: <http://www.conjur.com.br/2015-mar04/magistratura-celeridade-nao-reduzir-trabalhoamb?utm_source=dlvr.it\&utm_medium=facebook > . Acesso em 06/03/2015.

. Juizados especiais recebem milhões de novos casos. Disponível em: <http://www.conjur.com.br/2015-jan-22/juizados-especiais-recebem-milhoes-novos-casos2014>, acesso em 13/06/2015.

. Mudança no CPC aumentará numero de recursos que chegarão ao STJ, disponível em: <http://www.conjur.com.br/2015-mai-19/mudanca-cpc-aumentar-numero-recursos-chegamstj?utm_source=dlvr.it\&utm_medium=facebook>, acesso em 14/05/2015.

Apesar da baixa confiança judiciário recebe ação a cada segundo. Disponível em: <http://www.conjur.com.br/2014-nov-18/apesar-baixa-confianca-judiciario-recebe-acao-cadasegundo>. Aceso em 02/02/2015.

Entrevista com Lênio Steck. Disponível em: <http://www.conjur.com.br/2015-mai30/entrevista-lenio-luiz-streck-jurista-professor?utm_source=dlvr.it\&utm_medium=facebook>, acesso em 14/05/2015. 
TRIBUNA DO ADVOGADO, ano LXIV, fevereiro de 2015, número 545, páginas 6-7.

Tribunal de Justiça do Estado do Rio de Janeiro, Acórdão das Turmas Recursais no processo $\mathrm{n}^{\mathbf{0}}$ 0017651-31.2011.8.19.0042 - j. em 06/12/2011 - Juíza Paloma Rocha Douat Pessanha, que condenou a recorrente a devolver de forma simples o valor cobrado a título de tarifas, bem como a indenizar o consumidor por danos morais. Disponível em: <http://www4.tjrj.jus.br/ejud/ConsultaProcesso.aspx?N=20117000963766>. Acesso em $01 / 12 / 2014$.

Súmula do Tribunal de Justiça, disponível em: $<\mathrm{http} / / /$ webfarm.tjrj.jus.br/biblioteca/asp/textos_main.asp?codigo $=150637 \& d e s c=t i \& s e r v i d o r=1$ \&iIdioma $=0>$. Acesso em 24/02/2015.

Tribunal de Justiça do Estado do Rio de Janeiro, Acórdão das Turmas Recursais no processo no 2009.700.020680-5, j. em 27/04/2009, Juíza Gracia Cristina Moreira Do Rosario, que deu provimento ao recurso do fornecedor julgando improcedente pedido de indenização por danos morais em caso em que o consumidor não pode utilizar seu aparelho de telefonia móvel por duas semanas. Disponível em: <http://www4.tjrj.jus.br/consultaProcessoWebV2/consultaProc.do?numProcesso=2008.042.0243 19-1>. Acesso em 01/03/2015.

. Tribunal de Justiça do Estado do Rio de Janeiro, Acórdão das Turmas Recursais, no processo $^{\circ}$ 0007951-44.2014.8.19.0036 - j. em 18/12/2014 - Juiz Marcos Antonio Ribeiro De Moura Brito, que deu provimento a recurso julgando improcedente o pedido de devolução do valor cobrado a título de tarifas e também de danos morais. Disponível em: $<$ http://www4.tjrj.jus.br/ejud/ConsultaProcesso.aspx?N=20147006014207>. Acesso em 05/01/2015.

Tribunal de Justiça do Estado do Rio de Janeiro, Acórdão das Turmas Recursais, no processo $n^{\circ}$ 0009699-19.2011.8.19.0036 - j. em 28/06/2012 - Juiz Livingstone Dos Santos Silva Filho, que deu provimento a recurso e julgou procedente o pedido de danos morais em caso de bloqueio indevido de cartão de crédito. Disponível em: <http://www4.tjrj.jus.br/consultaProcessoWebV2/consultaProc.do?v=2\&FLAGNOME=\&back=1 \& tipoConsulta=publica\&numProcesso=2014.001.115408-1>. Acesso em 02/02/2015.

. Tribunal de Justiça do Estado do Rio de Janeiro, Acórdão das Turmas Recursais, no processo no 0023367-68.2013.8.19.0042 - j. em 02/12/2014 - Juíza Isabela Lobão Dos Santos, que deu provimento ao recurso e julgou improcedente pedido de indenização por danos morais decorrente de bloqueio indevido de cartão de crédito. Disponível em: <http://www4.tjrj.jus.br/ejud/ConsultaProcesso.aspx? $\mathrm{N}=20137001064670>$. Acesso em $02 / 02 / 2015$.

Tribunal de Justiça do Estado do Rio de Janeiro, Acórdão das Turmas Recursais, no processo $n^{\circ}$ 0092749-85.2012.8.19.0042 - j. em 17/07/2012 - Juíza Eduarda Monteiro De Castro Souza Campos, que deu provimento ao recurso e julgou procedente pedido de indenização por danos morais decorrente da cobrança indevida do plano LDN. Disponível em: 
<http://www4.tjrj.jus.br/ejud/ConsultaProcesso.aspx?N=20137000616669>.

Acesso

em $02 / 02 / 2015$.

. Tribunal de Justiça do Estado do Rio de Janeiro, Acórdão das Turmas Recursais, no processo $n^{\circ}$ 0020198-66.2013.8.19.0206 - j. em 12/12/2014 - Juíza Isabela Lobão Dos Santos, que deu provimento parcial ao recurso do consumidor mas julgou improcedente pedido de indenização por danos morais decorrente da cobrança indevida do plano LDN. Disponível em: <http://www4.tjrj.jus.br/ejud/ConsultaProcesso.aspx?N=20147005923790>. Acesso em $02 / 02 / 2015$

. Tribunal de Justiça do Estado do Rio de Janeiro, Acórdão das Turmas Recursais, no processo $n^{\circ}$ 0133487-73.2014.8.19.0001 - j. em 17/12/2014, Juiz Aylton Cardoso Vasconcellos , que julgou improcedente pedido de indenização por danos morais decorrente de suspensão

do serviço de eletricidade. Disponível em: $<$ http://www4.tjrj.jus.br/ejud/ConsultaProcesso.aspx?N=20147005959498>. Acesso em 02/02/2015. Acesso em 02/02/2015.

. Tribunal de Justiça do Estado do Rio de Janeiro, Acórdão das Turmas Recursais, no processo 2009.700.076598-3 - j. em 18/11/2009 - Juiz Ricardo Alberto Pereira - que deu provimento ao recurso para julgar procedente o pedido de danos morais em caso de suspensão indevida de energia elétrica. Disponível em: $<$ http://www4.tjrj.jus.br/ejud/ConsultaProcesso.aspx?N=2009.700.076598-3>. Acesso em $02 / 02 / 2015$.

Tribunal de Justiça do Estado do Rio de Janeiro. Acórdão em Ap. cív. no 0023658-68.2013.8.19.0042 - j. em 19/12/2014 - 27 Câmara Cível do Consumidor - Des.

Marcos Alcino De Azevedo Torres, que negou provimento à apelação do fornecedor, que visava reformar sentença que julgou procedente o pedido de devolução em dobro das tarifas. Disponível em: <http://www4.tjrj.jus.br/ejud/ConsultaProcesso.aspx?N=201400193246>. Acesso em $05 / 01 / 2015$

Superior Tribunal de Justiça, Reclamação no 4.892/PR (2010/0186855-4) - decisão monocrática do Ministro Raul Araújo, j. em 16/11/2010, que entendeu haver necessidade de comprovação da máfé do credor para haver a obrigatoriedade de devolução em dobro de tarifas cobradas indevidamente. Disponível em: $<$ https://ww2.stj.jus.br/processo/pesquisa/?termo=2010\%2F01868554\&aplicacao=processos.ea\&t ipoPesquisa $=$ tipoPesquisaGenerica\&chkordem $=$ DESC\&chkMorto=MORTO $>$. Acesso em $01 / 12 / 2014$.

Superior Tribunal de Justiça, REsp n $\mathrm{n}^{\mathrm{o}} 1.399 .931$ - Terceira Turma - Relator Ministro Sidnei Beneti, j. em 11/02/2014, que deu parcial provimento ao recurso especial para afastar a possibilidade de indenização por danos morais em caso de não entrega pelo fornecedor de tablet adquirido em site de compras pela internet. Disponível em:

<https://ww2.stj.jus.br/processo/pesquisa/?tipoPesquisa=tipoPesquisaNumeroRegistro\&termo=2 01302819034\& totalRegistrosPorPagina=40\&aplicacao=processos.ea>. Acesso em 03/01/2015. 
. Superior Tribunal de Justiça, REsp n ${ }^{\circ}$ 1.269.246- Quarta Turma - Ministro Luis Felipe Salomão, j. em 20/05/2014, que negou provimento ao recurso especial do consumidor em caso de pedido de indenização por danos morais por atraso de voo nacional. Disponível em: $<$ https://ww2.stj.jus.br/processo/pesquisa/?tipoPesquisa=tipoPesquisaNumeroRegistro\&termo=2 01101136580\&totalRegistrosPorPagina=40\&aplicacao=processos.ea>. Acesso em 03/01/2015.

Superior Tribunal de Justiça, REsp $\mathrm{n}^{\circ}$ 1.234.549- Terceira Turma - Ministro Massami Uyeda, j. em 01/12/2011, que negou provimento a recurso especial que visava reformar decisão do Tribunal de origem que jugou improcedente pleito indenizatório por danos morais em caso de entrega de imóvel com infiltrações, vazamentos e imperfeição do acabamento. Disponível em:

<https://ww2.stj.jus.br/processo/revista/documento/mediado/?componente=ATC\&sequencial=19 $377024 \&$ num_registro $=201100134201 \&$ data $=20120210 \&$ tipo $=5 \&$ formato $=P D F>$. Acesso em $02 / 02 / 2015$.

Superior Tribunal de Justiça, REsp n ${ }^{\circ}$ 489.325- Quarta Turma - $\quad$ Ministro Marco Buzzi, j. em 07/04/2003, que deu provimento a recurso especial para julgar improcedente pedido de danos morais em caso de aquisição de produto apodrecido. Disponível em: <https://ww2.stj.jus.br/processo/revista/documento/mediado/?componente=MON\&sequencial=6 96155\&num_registro=200201729563\&data $=20030409 \&$ formato $=P D F>$. Acesso em 02/02/2015.

Superior Tribunal de Justiça, REsp n ${ }^{\circ}$ 1.444.573- Terceira Turma - Ministro Ricardo Villas Boas Cueva, j. em 04/09/2014, que deu provimento a recurso especial entendendo que a retenção do consumidor em porta giratória de banco não era fato idôneo para ensejar indenização por abalo moral. Disponível em: <https://ww2.stj.jus.br/processo/revista/documento/mediado/?componente=ATC\&sequencial=38 $728617 \&$ num_registro $=201400669798 \&$ data $=20140917 \&$ tipo $=5 \&$ formato $=P D F>$. Acesso em $02 / 02 / 2015$.

Superior Tribunal de Justiça, REsp no 1.457.199, Ministro Paulo de Tarso Sanseverino, j. em 12/11/2014, que deu parcial provimento a recurso especial para declarar legal o sistema de avaliação de crédito denominado scoring o credit score. Disponível em: $<$ https://ww2.stj.jus.br/processo/pesquisa/?termo=REsp+1.457.199+\&aplicacao=processos.ea\&ti poPesquisa=tipoPesquisaGenerica\&chkordem=DESC\&chkMorto=MORTO $>$. Acesso em 04/03/2015.

Supremo Tribunal Federal, Ministro Marco Aurélio Mello, j. em 05/02/2015, que foi voto vencido, sendo certo que os demais sete ministros deram provimento ao recurso para declarar constitucional o art. $5^{\circ}$, cabeça, da Medida Provisória $\mathrm{n}^{\circ} 2.170-36$, de 23 de agosto de 2001, que permitia a capitalização de juros pelas instituições financeiras. Disponível em: <http://www.stf.jus.br/portal/processo/verProcessoAndamento.asp?incidente=2636792>. Acesso em 04/03/2015. 